\title{
Language Plots in Musical Spaces: A Response to Adams Bodomo and Manolete Mora
}

\author{
DANIEL AVORGBEDOR \\ The Ohio State University
}

\begin{abstract}
The commentary begins with by briefly reviewing UNESCO's activities in the documentation, preservation, and dissemination of cultural traditions worldwide, and particularly in sub-Saharan Africa. Suggestions are then made regarding how the observations reported by Bodomo \& Mora (2007) might be augmented by various theoretical, musical, and ethnolinguistic perspectives. The commentary also addresses challenges of designing and conducting research regarding integrative performance events and the construction, communication, and interpretation of cultural meaning.
\end{abstract}

Submitted 2007 July 18; accepted 2007 July 19

KEYWORDS: West Africa song dance story oral culture Dagaare Dagaaba bawaa

\section{ESSENTIAL CONTEXTS}

IT is important to begin this response by opening up to our readers some of the significant background factors that shape and thus illuminate the premises, methods, the general thrust of the essay and, perhaps, the rationale motivating site selection. First, I wish to begin by placing in a larger context the following statements from the article by Adams Bodomo and Manolete Mora, "Documenting Spoken and Sung Texts of the Dagaaba of West Africa" (2007).

[a] The importance of this documentation lies in the fact that traditional oral cultures are fast disappearing among some sections of such societies in the face of a ruthless process of globalization.... There is more than ever the need to document the cultural institutions, including language, music and dance, of such mainly oral cultures before they die out as a result of the rapid advance of globalization in which more dominant cultures easily drown out less dominant cultures.

[b] We have divided these recordings into 'bands' closely following the order in which they appear in the CD documentation that has been submitted to UNESCO.

[c] In terms of how to build on this research, a further field trip is planned to do a comprehensive visual documentation of this community in the form of an anthropological film documentary.

Since the 1950s the influential international organization, UNESCO, has formulated, published and systematically sought the implementation of specific "policies," especially those concerning the documentation, preservation, and dissemination (important terms) of music, dance and other cultural traditions, worldwide. Eventually, as each country (especially postcolonial societies) redefines its new postcolonial identities and through changing politics of culture, they would invariably do so largely under the perforce and motivations of UNESCO's legislations. The implications of this organization's superstructures and hyperpolitics for methods and goals of research work in the academe and in the contexts of new nationalisms and global citizenship cannot, therefore, be disputed, such as encapsulated in the essay by Bodomo and Mora. 
UNESCO has thus played a significant role in the emergence of innovative cultural and ideological practices which are purported to improve human living standards, worldwide. These policies and practices are also formulated and pursued in the realms of cultural production, including music and dance and with emphasis on the three practical means highlighted above, that is, documentation, preservation, and dissemination. Over the years each country member has been encouraged to produce a "cultural policy" manual, drawing on UNESCO'S guidelines and samples, most of which were seeded during regional and international conferences. Thus, for example, in 1975 the Africa Regional Rostrum was opened in Accra, Ghana and activities from that meeting resulted in elaborate compilations of "representative" ethnic and regional music and dance traditions from various African countries that should be recommended (i.e., after "documentation") for broadcast on African radio stations. The radio broadcasts represent part of the "dissemination" strategies and objectives, and the materials to broadcast were often collected by fieldworkers of various academic and disciplinary standing. Soon after this meeting, Ghana's "cultural policy" handbook, The Cultural Policy of Ghana (Paris: UNESCO, 1976) was published.

These preliminary examples are, however, best understood in the light of the following select publications that would have lasting consequences on the objectives and modes of research conduct that are based largely on the premise that cultural and musical traditions are on the verge of extinction and encroachments and that these traditions need to be rescued, preserved, and revived somehow:

UNESCO, A Practical Guide to the World Decade for Cultural Development. 1988-1997. (Paris, 1987)

Music in the Dialogue of Cultures: Traditional Music and Cultural Policy. Max Peter Baumann and Ulrich Wegner, (Eds.) Intercultural Music Studies, vol. 2. Wilhelmshaven: Florian Noetzel Verlag. 1991. [See, for example, the essay on Africa by Kwabena J.H. Nketia, "Music and Cultural Policy in Contemporary Africa," pp. 77-94.]

UNESCO, Interrelations of Cultures, their Contribution to International Understanding. (Paris, 1953)

Creating a Wider Interest in TraditionalMusic. Proceedings of a Conference Held in Berlin in Cooperation with the International Music Council, 12th to the 17th June 1967. Alain Daniélou et al., eds. (UNESCO collection of representative works, Berlin, International Institute for Comparative Music Studies and Documentation,1967)

As of today, the impact of UNESCO reverberates with even subtle yet vibrant persuasions, engaging the duty and attention of scholars and practitioners of diverse disciplinary background. For example, details of member countries, charges and obligations, categories of "culture" and issues if copyright, are available in the online report, "Convention for the Safeguarding of the Intangible Cultural Heritage" [http://unesdoc.unesco.org/images/0013/001325/132540e.pdf]; general information from the UNESCO'S main website are accessible at: http://portal.unesco.org/culture/en.

To conclude this introduction, it is worth mentioning that that I personally serve as a local (i.e., Ghana and nearby countries) "chairperson" of the functionaries of another UNESCO'S subsidiaries devoted to the "rescuing and preserving" of world cultures: "International Committee on Urgent Anthropological and Ethnological Research (note "Urgent"]; this committee publishes a bulletin, ICUAER (acronym for the committee). The following text (in addition to the committee's name) summarize its goals:

"Our Commission's work is entirely devoted to assist in safeguarding and documenting endangered cultural heritage, especially in Third World countries... Will you kindly join our endeavours and co-operate in search for those cultural and/or social traits which are mostly endangered at present, then please fill in this Questionnaire and send it to our Secretariat." (from questionnaire form dated "Vienna, 2001" and inserted in the 19992000 ICUAER Bulletin, No. 40.) 
This clear statement from Urgent Anthropology clarifies further the authors' rationale [a] above. UNESCO's commissions and committees have also encouraged the recording and publication of a range of musical cultures; the authors' accompanying music examples, which are described as deriving from "the CD documentation that has been submitted to UNESCO" (i.e., statement [b] above), therefore, provide a good continuation of these institutionalized practices.

There are major questions about the overall conception, design and execution of this research work by Mora and Bodomo. However, specific questions pertaining to theory, method and general scholarly significance of the paper are regrettably preempted and thus mitigated by the title phrase and the background I have elaborated above. For example, "Documenting..." does not immediately suggest any substantial commitment to advancing general knowledge, tools, and perspectives through the employment of innovative research strategies and analysis; neither does it frame the data in critical perspectives of the related literature and scholarship. There are, however, important aspects of the analytical procedures and conclusions that must be discussed and I have selected a few sites of general concern in order to help the reader grasp the types and relevances of interpretations and conclusions.

Urgent Anthropology and the general UNESCO presumptions about "extinction" must be interpreted and thus slightly applaud in the light general insecurities in certain quarters about possible "loss" of rooted traditions due to the onslaught of globalization and increasing human mobility. This remark partly upholds Bodomo and Mora and partly interrogates them for not giving sufficient thought to the vibrancy and ongoing creativities, as confirmed by the mutual reinforcements of their urban and rural data. In addition, an unguarded concern with "extinction" brings to the fore the self-limiting and loosely formulated "scientific" constructs that distinguished the early days of folklore, ethnomusicology, and anthropology.

In compiling the relevant portions of the essay for this response, I had to turn to other sources somewhere else in order to find a concrete statement of purpose. For example, according to the essay,

"The main intention of the project is to document songs, proverbs, riddles, spoken and sung folktales, instrumental music, and dance performances, in particular báwáá, in their "natural" contexts."

However, for any mention of theory at all one has to turn to another source (i.e., by same authors and on a similar research subject) where the "theoretical perspectives" and "significance" are stated clearly:

"From a theoretical perspective, this project aims at producing original field data for integrated linguistic and musical analyses.... This study is significant for interdisciplinary research into forms and modes of cultural expression from any part of the world."

(http://www.hku.hk/linguist/staff/Folktales.html)

It is clear this is a team project involving a linguist (Bodomo) and a musicologist (Mora) and, simply, they are engaged in a basic interdisciplinary study of music and language and from a "comparative" viewpoint. As indicated earlier, the framework or premise of "extinction" under the UNESCO's established practices both absolve and at the same hold Bodomo and Mora on a higher ground, both for the sake of the scientific community and on behalf of the society under study. The analyses provided, for example, overlook very important contexts, both in respect to the data and the extant literature- these contexts cannot be slighted if the authors truly seek to unravel the "cultural meaning" of the texts they have collected.

First, the authors would have been able to arrive at some of complex, multiple forces shaping the continuity, innovation and possible threats of "extinction" of Dagaare music, dance and language. A discussion of the mutual interactions of, for example, oral and written traditions is necessary in gaining a wider sense and direction in meaning of the folktale, recitations, song, etc. and the various ways in which they co-opt texts and ideas from popular culture and foreign tongues (e.g., French texts). An extended analysis with cultural sensitivity will reveal the significant influences of "classroom" or published folktales (especially those compiled from within and without by early missionaries and contemporary authors of class texts). The classroom itself, even in the light of conflicting statistics of low school attendance in that part of northern Ghana where the research was based, has played significant roles shaping new approaches 
to learning processes, performance, and contextual framing of folktale traditions, a general trend in most African and world cultures.

The once systematic introduction and final institutionalization of new traditions of local xylophone and choral music into the Dagaaba Catholic churches (with some experimental nuns and priests employing a mix of Western and original forms of notation) also present another important feature of the plural but influential sources that inform contemporary Dagaaba performance traditions. It can, therefore, be very misleading to label cultures prematurely as "mainly oral"; it will have important consequences for our analytical procedures and conclusions. The general objectives of the research did not encourage an extended field study and this time factor also severely limits the range of informants and contexts that would significantly increase the contextual dynamics of the performances and the sophistication of the interpretive frames employed. (The authors spent "one month in 2000"; see http://www.hku.hk/linguist/staff/lang\&music finalreport.html ). The given "ethnolinguistic and musicological" analyses thus lack an in-depth ethnographic explorations, as will be discussed further below.

Most contemporary researchers (even in some early ethnocentric travel accounts) appropriately begin the subject of African music, dance, masquerade, poetry, etc. usually by raising the importance of integrative or holistic approaches, both in conception and in practice. Such basic understanding is lacking in the uncritical employment of discreet categories such as in the goal statement quoted above:

"The main intention of the project is to document songs, proverbs, riddles, spoken and sung folktales, instrumental music, and dance performances, in particular báwáá, in their "natural" contexts."

Elsewhere, the authors acknowledge this important interrelationship:

In West Africa, among the rural dwellers of the Dagaaba and Akan ethnolinguistic groups of Ghana, the folktale incorporates various cultural forms, such as language, music, dance and other performing arts. (http://www.hku.hk/linguist/staff/Folktales.html )

Two important sites that would truly generate the deep "cultural meaning" sought as the authors amplify the texts through "free translation and glosses" would thus include the local ontological status of "music," especially in its holistic outlook and extended definitions. There are a few important studies in African music and related arts that would certainly provide the assumptions and subsequent analysis of the range of performance events covered in the research project. ] These would include, for example, Harold Scheub's classic essay (1970); Kofi Agawu's, African Rhythm . . . (1995); "Language and Music in the LuNa Drumming of Dagbon .. . “ by Mary E. Kropp Dakubu and Cathleen Read (1985); David Locke's Drum Damba (1990); Paul Neeley's People of the Drum of God, Come! . . . (1994); and Peter Seitel's (1980) See So That We May See. . .

These basic sources and additional ones specific to the Dagaaba are, therefore, necessary in developing not only a deep-structural analysis of the performance events in context, they will also provide a more elegant ways of transcribing/representing and interpreting the texts. In this way, the entire project will stand to make definite contributions to both method and theory in the study of language-music relationships, both in Ghana and in other world cultures. For example, Seitel's work, which is based on Dennis Tedlock's model of transcription (1972).

Modes and techniques of transcription are not only a means at approximating a "reality," they also serve as important rhetorical devices and sometimes make effective tools in clarifying the integrative features and functions in African performances, no matter how imperfect these tools are. A basic awareness and an application of some of the principles and techniques in these sources will also support the authors' "interdisciplinary" project and the challenges in defining music and language relationships. Apart from the two-level tone marks (Dagaare is a tone language with two basic levels, high - low) no other means-such as traditional Western notation - are employed to register the performance features. The ongoing contested relationships between "music and language" are best investigated also though the presentation of selective 
features of related performance traditions, namely, panegyrics (praise song/poetry) and appellations (name calling/performance and surrogate drumming). As documented variously in the literature cited above and in the numerous musical tracks accompanying the essay, these examples abound in the northern sector of Ghana and their specific analyses in context will broaden our understanding of the "tonal" nature of music and language and thus explain why and how tension exists not only between the two, but also between our epistemological foundations and the ontological statutes of music and language in local cultures.

It is a bit of surprise to read (to me, at least) that Bodomo and Mora are discovering something "new" in regard to tone-tune relationships:

Two University researchers, and friends, set out to investigate the matter. In the process, their University-funded project has been picked up by the United Nations Educational, Scientific and Cultural Organisation (UNESCO) for use in its World Heritage

series to record and preserve cultural traditions from around the world. Associate Professors Dr Adams Bodomo of the Department of Linguistics and Dr Manolete Mora of the Department of Music were keen to test emerging theories that question the accepted wisdom about songs in tonal languages. Until recently, in the study of African music, the meaning of the words was assumed to take precedence over melodic beauty, so if a word had a high tone, the melody would shift to a high note. The two men went to Dr Bodomo's native Ghana to record songs, folk tales and music and dance performances by the country's Dagaare-speaking people. Dagaare has two tones. They then spent months sifting through the recordings, pulling out those that were intellectually and culturally important and of good quality, and analysing the results. What they found supported suspicions about the role of language in determining melody. "We found the correlation was weak and not as strong as it has been made out to be. Aesthetic considerations are much more important than previously thought," Dr Mora said. "I may be sticking my neck out at this point to say this. ("The Language of Music" May 2005 Hong Kong University Bulletin, Vol. 6 No. 3, May 31: http://web.hku.hk/ bulletin/Bulletin_2005_May.pdf)

The fact that the "correlation was weak" is not really a new insight; many scholars have clarified such relationships, including an earlier work by Kofi Agawu (1988). The essay at hand is the right place to establish further grounds for making any "new" claim about tone-tune correlations and such grounds are not sufficiently demonstrated in the essay. (I am aware that the authors are engaged in ongoing projects on "tone-tune" and "tune-tone" relationships (http://www.hku.hk/linguist/staff/Folktales.html).

Most linguistic and musical studies of African tone languages often are content with two or three basic tone distinctions, ignoring important subtleties and slides that exist between the basic tones; these subtleties have important musical and linguistic ramifications and which must be considered by future research. Also, we cannot make definitive conclusions based on studies emanating from one village or social unit; we must consider a broad range of genres (our categories), repertories, specific performance contexts and compare our data across other tone-language areas. In this case, a "weak" or even "strong" correlation between tone and tune cannot be safely sustained till we consider and follow these suggestions.

Ethnolinguistic discussions can aid the identification of important musical and language cues, with a view toward their interdependence and hence communicative perforce. For example, the following texts from Listening examples 17-25 and explained in the general exegesis require additional cultural-contextual input in order to arrive the "linguistic and cultural meaning" sought:

"Whether I sleep or not, no one can know exactly."

This text is in relation to local beliefs and their continuities urban areas, especially the subject of witcheraft. An extended inquiry would reveal that most African societies believe that witches ("wizard" is the term normally employed by Africans for male witches) become active, holding meetings at nights. The nocturnal activities also frequently target specific bodies or victims in their sleep. As such, anyone suspecting such 
foul play on him/her would want to stay the eyes open in order to either avoid or "catch' the night visitors. This background would add significant cultural information to that one line.

Similarly, the following line would require additional contextual information if we grasp its full import:

"A calabash full of ashes and all such things are what Christians dislike."

The Dagaaba are part of the northern zone of Ghana were calabashes and gourds continue to function plurally: as domestic utensils, musical instruments derive wholly or partly from them, and they serve important decorative and ritual purposes. While these descriptions apply largely to many other African societies, the general ecology and patterns of daily life emphasize the gourd and calabash in specific ways. The lone-line text above captures not only most of these associations but also the important dialectic of "belonging" and contestations in both physical and spiritual matters and between adherents of indigenous religions and the those of the Christian faith. In addition, there is also blurred path between the indigenous practices and Christianity, which sometimes privileges some Christians double: certain weak or uncommitted Christian individuals would often "sneak" back-and-forth between the indigenous and Christian practices. Sometimes the indigenous practitioners would either indirectly or openly mock at these "double-life" Christians, either through song texts, movement, storytelling, or ironical remarks in public spaces. Thus, the line above could carry several meanings and influence, depending on the composition of the audience, the performer(s), the occasion and history of the people. Both calabash and ash are wellknown potent ritual items encountered in many indigenous rituals. (Local Catholics also employ the ash during the celebration of Ash Wednesday, for example.) These are just two examples of how an ethnolinguistic approach could amplify the contextual data needed to compose glosses and free translations that are rich in cultural information. In addition, the researcher would corroborate evidence and conclusion through secondary analysis (the limited references are disappointing) and by spot-checking with informants other than those officially employed to help with translation projects and across cross-sections of the rural and urban units studied. In conclusion, I wonder why Vetter (2000) is cited; this is just a review and the reviewed work (Trevor Wiggins) is more relevant to the essay than the Vetter's review. In a curious way, Wiggings is properly cited in an older paper, of which this essay is almost an exact copy. (http://www.hku.hk/linguist/staff/Songtextdances.UNESCO web.pdf)

\section{NOTE}

[1] Dr. Avorgbedor is associate professor in the School of Music and the Department of African American and African Studies at The Ohio State University, Columbus, Ohio, USA.

\section{REFERENCES}

Agawu, K. (1995). African Rhythm: A Northern Ewe Perspective. Cambridge and New York: Cambridge University Press.

Bodomo, A., \& Mora, M. (2007). "Documenting Spoken and Sung Texts of the Dagaaba of West Africa" (2007). Empirical Musicology Review, Vol. 2, No. 3, pp. 103-109

Dakubu, M.E.K., \& Read, C. (1985). Language and Music in the LuNa Drumming of Dagbon: A Preliminary Study, Papers in Ghanaian Linguistics 5. Legon: Institute of African Studies, 1985, pp. 20-31.

Locke, D. (1994). Drum Damba. Crown Point, IN: White Cliffs Media Company. 
Neeley, P. (1994). People of the Drum of God, Come! Ethnography of a Speech Surrogate Performance Paradigm. Dallas: International Museum of Cultures.

Scheub, H. (1970). The techniques of the expansible image in Xhosa Ntsomi performances. Research in African Literatures, Vol. 112, pp. 119-146.

Seitel P. (1980). See So That We May See: Performances and Interpretations of Traditional Tales from Tanzania. Bloomington: Indiana University Press.

Tedlock, D. (1972). Finding the Center: Narrative Poetry of the Zuni Indians. New York: Dial Press. 